\title{
Optimasi Sistem Irigasi Lahan Tada Hujan Menggunakan Algoritma Ant Colony Optimization Berbasis Tenaga Surya
}

\author{
Abdul Haris ${ }^{1}$; Hengki Sikumbang ${ }^{2}$; Hendra Rahmawan ${ }^{3}$; Sri Wahjuni ${ }^{4}$; Heru Sukoco ${ }^{5}$; \\ Shelvie Nidya Neyman ${ }^{6}$ :Muhammad Jafar Elly ${ }^{7}$ \\ 1, 3, 4, 5, 6 Department of Computer Science Bogor Agriculture University, Indonesia \\ ${ }^{2,7}$ Institut Teknologi PLN Jakarta, Indonesia \\ 1ªbdulharis@apps.ipb.ac.id \\ ${ }^{2}$ hengki@itpln.ac.id \\ ${ }^{3}$ hrahmawan@apps.ipb.ac.id \\ ${ }^{4}$ my_juni04@apps.ipb.ac.id \\ ${ }^{5}$ hsrkom@ipb.ac.id \\ ${ }^{6}$ shelvie@apps.ipb.ac.id \\ 7 jafar.elly@itpln.ac.id
}

\begin{abstract}
Indonesia is a country that has vast agriculture and has a majority source of income as farmer. The agriculture area still cannot be optimized considering that still a lot of dry agriculture land and have not got good irrigation system, several problems that cause are still a lot of dry agriculture which higher position of irrigation system available and there are limited land so that if irrigation system built or DAM then operational coast outweigh of impact on the land, another problem occurs is limited ability of community for built independent and modern irrigation system so that assistance is needed and technology that can be utilized as resource for built independent and modern irrigation system. One of potential resource in Indonesia is energy of sun which can be converted to electric power, this is energy very much in Indonesia, so that can be using as energy to pump water from springs to be distributed to dry agriculture land. To be able to reduce human power and monitoring this paper using Ant Colony Optimization as computation system. This algorithm used to optimized water distribution evenly on dry agriculture land which is adapted to the soil conditions.
\end{abstract}

Keywords: Irrigation System; Dry Agriculture Land; Ant Colony Optimization

\section{ABSTRAK}

Indonesia merupakan negara yang memiliki lahan pertanian yang cukup luas dan merupakan sumber panghasilan mayoritas penduduknya yang memiliki mata pencaharian utama sebagai petani, luas wilayah pertaniannya masih belum dapat dioptimalkan mengingat masih banyak lahan yang belum mendapatkan sistem irigasi yang baik, beberapa masalah yang menjadi penyebabnya adalah masih banyak lahan yang posisinya lebih tinggi dari sistem irigasi yang ada dan banyaknya lahan yang lingkupnya masih terbatas sehingga jika dibangun sistem irigasi atau bendungan maka lebih besar biaya operasionalnya daripada dampak pada lahannya, masalah lain yang terjadi adalah keterbatasan kempuan masyarakat untuk membangun sistem irigasi yang mandiri dan modern sehingga diperlukan pendampingan dan teknologi yang mampu dimanfaatkan sebagai sumber daya untuk membangun sistem irigasi yang mandiri dan modern, salah satu sumber daya yang memiliki potensi adalah energi matahari yang dikonversikan menjadi energi listrik, energi ini sangat berlimpah di Indonesia, sehingga dapat digunakan sebagai energi untuk memompa air dari sumbernya agar dapat di distribusikan pada lahan tada hujan. Untuk mengurangi tenaga manusia dan mempermudah monitoring pada paper ini menggunakan Algoritma Ant Colony Optimization pada sistem komputasinya, Algoritma ini digunakan untuk melakukan optimalisasi distribusi air secara merata pada lahan yang disesuaikan dengan kondisi tanah.

Kata kunci: Sistem Irigasi; Lahan Tada Hujan; Ant Colony Optimization 


\section{PENDAHULUAN}

Luas wilayah di Indonesia mencapai lebih kurang 1.9 juta $\mathrm{km}^{2}$ yang mayoritas penduduknya bermata pencaharian sebagai petani hal ini belum berbanding lurus dengan kebutuhan sumber irigasi yang baik jika dibandingkan dengan kondisi lahan pertanian yang produktif sangat tidak sebanding dikarenakan masih luasnya lahan pertanian yang belum dioptimalkan yang mencapai 76,20 juta hektar dengan 70,70 juta hektar berada didataran rendah dan 5,50 juta hektar yang berada didataran tinggi, sebagian lahan tersebut telah dimanfaatkan dengan baik untuk pertanian namun sebagian lainya sekitar 35,50 juta hektar belum dimanfaatkan secara optimal [1].

Untuk lahan pertanian yang belum dapat dimanfaatkan secara optimal dapat dioptimalkan dengan memanfaatkan sumber daya yang telah tersedia agar taraf hidup petani dapat ditingkatkan, kondisi seperti ini perlu perhatian untuk pengembangan terlebih lahan yang berada didaratan tinggi merupakan lahan tada hujan sehingga diperlukan sistem irigasi yang mandiri mengingat sulitnya pembangunan DAM namun lahan ini sangat perlu dioptimalkan karena hanya dapat diolah pada saat muasim hujan saja.

Rata-rata lahan ini menjadi sumber penghasilan utama petani sehingga dampaknya, pemilik lahan ini tidak bisa meningkatkan tarap hidupnya, sebagian ada yang di daerah yang dekat dengan sumber air dapat memanfaatkan air dengan memompa air dengan menggunakan mesin Disel atau mesin pemompa air dengan bahan bakkar bensin ini mengakibatkan biaya yang cukup tinggi karena sangat bergantung dengan harga Bahan Bakar Minyak (BBM) sehingga biaya operasional yang di keluarkan lebih tinggi dari pada hasil panen. Kondisi seperti ini membuat para petani menjadi enggan mongolah lahannya jika masuk musim kemarau.

Berdasarkan data BPS jumlah petani yang miskin di Indonesia tahun 2004 mencapai 37,34 juta jiwa hal ini salah satu faktornya adalah masih banyaknya lahan yang belum dapat dimanfaatkan dengan baik [2] Disisi lain wilayah Indonesia merupakan wilayah tropis yang secara astronomi terbentang antara $6^{0} \mathrm{LU}-11^{0} \mathrm{LS}$ dan $95^{\circ} \mathrm{BT}-141^{\circ} \mathrm{BT}$ yang merupakan wilayah yang kaya akan sumber daya matahari dengan rata-rata $4,5 \mathrm{kWh} / \mathrm{m}^{2}$ per hari untuk wilayah barat Indonesia sampai dengan $5,1 \mathrm{kWh} / \mathrm{m}^{2}$ per hari untuk wilayah timur Indonesia hal ini sangat potensial untuk dimanfaatkan sebagai energi alternative [3][4] untuk rata-rata wilayah Indonesia secara keseluruhan $4,8 \mathrm{kWh} / \mathrm{m}^{2}$ per hari [5][6][7] , sumber daya ini dapat di konversi menjadi energi listrik dengan menggunakan Photovoltaic sehingga dapat dimanfaatkan sebagai energi pemompa air untuk kebutuhan irigasi lahan tada hujan. Dengan adanya sistem ini lahan tada hujan dapat dimanfaatkan oleh petani secara makasimal.

Penggunaan Sistem Komputasi Ant Colony Optimization adalah untuk mengoptimalkan distribusi air agar sesuai dengan kebutuhan tanah dan tanaman berdasarkan tingkat kekeringan tanah, luas tanah yang kering dan pengaruh panjang pipa yang digunakan dari sumber air sampai ke lahan yang membutuhkan air. Indikator yang digunakan adalah luas tanah yang kering digunakan sebagai Pheromone $\tau_{i, j}^{\alpha}$ dan tingkat kekeringan digunakan sebagai nilai alpha " $\alpha$ " yang mempengaruhi pheromone sementara panjang pipa $\eta_{i, j}^{\beta}$ digunakan sebagai indikator panjangnya jarak yang ditempuh oleh air melalui pipa dan $\beta$ nilai yang mempengaruhi kecendrungan untuk memilih air di aliri berdasarkan panjang pipa. Target dari penelitian yang ditulis pada paper ini adalah distribusi air akan menggunakan dua indikator tingkat kekeringan tanah yang sangat membutuhkan air dan yang berikutnya adalah panjang pipa yang akan di aliri oleh air dengan masing - masing memiliki nilai kecendrungan yang mempengaruhi sehingga air dapat dialiri sesuai dengan bebutuhan. 


\section{METODE PENELITIAN}

Pada paper ini akan menyajikan penyelesaian masalah distribusi air pada lahan tada hujan dengan pendekatan kuantitatif yang didasarkan luas tanah yang kering dan panjang pipa yang akan dialiri air sebagai indikator utama, masing - masing indikator tersebut dipengaruhi oleh nilai $\alpha$ yang merupakan tingkat kekeringan tanah dan $\beta$ yang merupakan tekanan debit air dan kemiringan tanah jika nilai $\alpha$ yang lebih tinggi maka air akan di distribusi berdasarkan tingkat kekeringan tanah namun jika nilai $\beta$ maka air akan didistribusi berdasarkan panjang pipa, kondisi seperti ini dapat mendistribusikan air pada lahan sesuai dengan kebutuhan sensor sehingga dapat terjadi pemerataan.

Lahan yang diuji coba adalah lahan dengan luas 3 meter di kali 3 meter dengan kondisi kering dan basah, untuk kondisi pada lahan menggunakan indeks pada tabel berikut:

Tabel 1. Indeks Kondisi tanah

\begin{tabular}{lc}
\hline \multicolumn{1}{c}{ Indeks kondisi tanah } & Value \\
\hline Kering & $0-25$ \\
Sedang & $26-50$ \\
Basah & $51-75$ \\
Sangat Basah & $76-100$ \\
\hline
\end{tabular}

Pada tabel diatas disajikan tabel kodisi tanah yang menjadi indikator untuk distribusi air data tersebut didapatkan dari hasil uji coba dengan menggunakan sensor soil moisture dengan rekayasa 4 kondisi tanah. Kemudian untuk distribusi panjang pipa digunakan untuk 4 posisi sensor adalah bervariasi antara 0,5 meter sampai dengan 2 meter, ini diuji dengan 2 titik yang memiliki posisi yang lebih tinggi 1 titik di posisi yang sedang dan 1 titik diposisi yang lebih rendah, dalam paper ini sumber energi yang digunakan adalah Solar panel yang dipasang untuk memompa Air dari sumber air yang digali dan nantinya akan di tampung ke pada bak penampung di posisi yang tinggi dengan ketinggian 2 meter dari atas lahan irigasi. Berikut adalah konsep sistem irigasi dan teknologi tenaga suryanya:

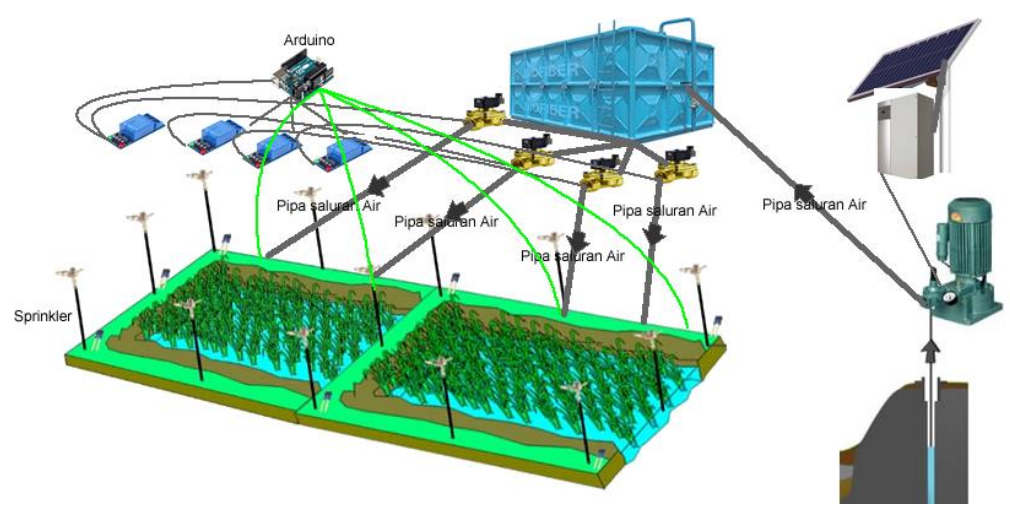

Gambar 1. Konsep sistem Irigasi

Dari kondisi tersebut kemudian dilakukan instalasi pada mikrokontroler menggunakan Arduino Uno sebagai mesin pengendali dengan menggunakan Algoritma Ant Colony Optimization dengan data indeks kondisi tanah seperti pada tabel 1 diatas, pada percobaan yang telah dilakukan pada masing - masing sensor mewakili 0,25 meter sebagai nilai luas tanah menggunakan persamaan $\tau_{i, j}^{\alpha}$ yang dipengaruhi oleh data pada tabel 1 diatas yang merupakan nilai dari $\alpha$ serta untuk panjang pipa dihitung menggunakan persamaan $\eta_{i, j}^{\beta}$ dengan dipengaruhi oleh nilai $\beta$ maka jika sensor 
mendapatkan data sesuai dengan rentang nilai yang telah di set tersebut maka nanti akan dibandingkan juga dengan panjang pipa yang akan dilewati oleh air jika kondisi indeks tanah sangat kuat mempengaruhi maka probabilitas air akan mengalir berdasarkan kondisi tanah namun jika probabilitas panjang pipa lebih mendominasi maka air akan didistribusi berdasarkan panjang pipa dalam hal ini pipa yang paling pendek dan posisi rendah akan di distribusi air. Berikut adalah persamaan probabilitas pada Ant Colony Optimization yang digunakan:

$$
P_{i, j}=\frac{\left(\tau_{i, j}^{\alpha}\right)\left(\eta_{i, j}^{\beta}\right)}{\sum\left(\tau_{i, j}^{\alpha}\right)\left(\eta_{i, j}^{\beta}\right)}
$$

Persamaan diatas digunakan untuk menentukan penentuan aliran air akan didistribusikan yang berdasarkan kecendrungan $\tau_{i, j}^{\alpha}$ yang didasarkan oleh kondisi tanah dan $\eta_{i, j}^{\beta}$ panjang pipa dan kondisi posisi tanah yang menentukan kedua persamaaan tersebut masing - masing dipengaruhi oleh nilai $\alpha$ dan nilai $\beta$. Pada proses update tingkat kekeringan tanah pada iterasinya menggunakan persamaan sebagai berikut:

$$
\tau_{i, j}^{\alpha}=(1-\rho) \tau_{i, j}^{\alpha}+\Delta \tau_{i, j}^{\alpha}
$$

Dimana $\tau_{i, j}^{\alpha}$ merupakan perubahan nilai kondisi tanah terbaru yang didapat dari pengurangan nilai konstanta yang dikurangi dengan nilai $\rho$ sebagai proses evorasi kondisi tanah yang belum di distribusikan air dan yang sudah di didistribusikan air sehingga nilai tersebut selalu berubah menyesuaikan kondisi tanah berdasarkan air yang terdistribusi, nilai tersebut dikalikan dengan nilai kondisi tanah yang sebelumnya ditambah dengan nilai $\Delta \tau_{i, j}^{\alpha}$ nilai ini merupakan nilai tekanan debit air yang dihasilkan dari sumber air dan didistribusi ke lahan yang membutuhkan air. Kemudian persamaan perubahan nilai panjang pipa dan posisi tanah menggunakan persamaan sebagai berikut :

$$
\eta_{i, j}^{\beta}=(1-\rho) \eta_{i, j}^{\beta}+\Delta \eta_{i, j}^{\beta}
$$

Dari persamaan diatas digunakan untuk update pemilihan jarak yang harus ditempuh oleh air yang dipilih dengan nilai dipengaruhi oleh $\Delta \mathrm{n}_{i, j}^{\beta}$ yang merupakan nilai jarak yang harus ditempuh dengan dengan dipengaruhi oleh tekanan dari debit air.

Tabel 2. Data dari 4 buah sensor

\begin{tabular}{crlllllllll}
\hline Time & \multicolumn{1}{c}{$\tau 1$} & $\tau 2$ & $\tau 3$ & $\tau 4$ & $\alpha$ & $\eta 1$ & $\eta 2$ & $\eta 3$ & $\eta 4$ & $\beta$ \\
\hline 1 & 13 & 27,5 & 78,2 & 12 & 0,5 & 0,5 & 1,5 & 1 & 2,5 & 0,3 \\
2 & 13,5 & 27,8 & 78,4 & 12 & 0,7 & 0,5 & 1,5 & 1 & 2,5 & 0,4 \\
3 & 13,4 & 29,3 & 79,3 & 12 & 0,3 & 0,5 & 1,5 & 1 & 2,5 & 0,2 \\
4 & 13 & 29,5 & 79,5 & 12 & 0,4 & 0,5 & 1,5 & 1 & 2,5 & 0,3 \\
5 & 14 & 30,4 & 79,8 & 12 & 0,3 & 0,5 & 1,5 & 1 & 2,5 & 0,2 \\
6 & 27 & 40,1 & 80,1 & 13 & 0,7 & 0,5 & 1,5 & 1 & 2,5 & 0,2 \\
7 & 27,3 & 40,3 & 80,2 & 13 & 0,2 & 0,5 & 1,5 & 1 & 2,5 & 0,1 \\
8 & 27,4 & 40,5 & 80,1 & 13 & 0,3 & 0,5 & 1,5 & 1 & 2,5 & 0,2 \\
9 & 28 & 40,7 & 82,1 & 13 & 0,2 & 0,5 & 1,5 & 1 & 2,5 & 0,2
\end{tabular}




\begin{tabular}{lllllllllll}
\hline 10 & 28,8 & 40,9 & 82,5 & 13 & 0,3 & 0,5 & 1,5 & 1 & 2,5 & 0,2 \\
11 & 29,1 & 50,1 & 83,2 & 13 & 0,3 & 0,5 & 1,5 & 1 & 2,5 & 0,2 \\
\hline
\end{tabular}

Dari tabel 2 diatas dapat dilihat perbandingan nilai kondisi tanah masing-masing sensor dimana $\tau$ menunjukan nilai dari masing - masing sensor yang dipasang pada lahan dengan luas sampel dan tingkat kekeringan yang yang bervariasi pada waktu yang berbeda $\tau 1$ menunjukan posisi sensor $1, \tau 2$ menunjukan posisi sensor 2 dan seterusnya Sementara nilai $\alpha$ adalah nilai yang mempengaruhi $\tau$ dan nilai $\beta$ merupakan nilai yang mempengaruhi nilai $\eta$ makin tinggi nilai $\alpha$ maka makin besar kemungkinan air didisteribusi berdasarkan kondisi tanah sebaliknya makin tinggi nilai $\beta$ maka makin tinggi pula air dialirkan berdasarkan panjang pipa dan tingkat kemiringan tanah kondisi tidak akan mempertimbangkan kondisi tanah yang kering atau basah selama kondisi tanah yang lebih rendah maka air akan didistribusi ke lokasi yang lebih rendah. Dari hasil pengujian yang telah dilakuakan didapatkan hasil sebagai berikut:

Tabel 3. Hasil Pengujian sensor 1

\begin{tabular}{cccc}
\hline $\begin{array}{c}\text { Kondisi } \\
\text { Tanah }\end{array}$ & P.Pipa & $\sum\left(\tau_{i, j}^{\alpha}\right)\left(\eta_{i, j}^{\beta}\right)$ & $P_{i, j}$ \\
\hline 5,24 & 1,13 & 5,92 & 0,67 \\
10,25 & 1,18 & 12,06 & 0,72 \\
2,75 & 1,08 & 2,99 & 0,61 \\
3,87 & 1,13 & 4,37 & 0,66 \\
2,79 & 1,18 & 3,28 & 0,66 \\
13,25 & 1,08 & 14,37 & 0,62 \\
2,09 & 1,28 & 2,67 & 0,68 \\
3,04 & 1,22 & 3,72 & 0,66 \\
1,45 & 1,13 & 1,64 & 0,59 \\
3,04 & 1,28 & 3,88 & 0,68 \\
1,48 & 1,08 & 1,60 & 0,57 \\
\hline
\end{tabular}

Dari tabel 3 diatas pada sensor pertama dapat dilihat bahwa nilai $\alpha$ sangat dominan mempengaruhi nilai $\tau$ sehingga kecendrungan air akan di distribusi ke lahan berdasarkan sensor 1 sangat tinggi dengan mengabaikan panjang pipa dan posisi ketinggian tanah seperti yang dapat dilihat pada tabel 3 diatas.

\section{HASIL DAN PEMBAHASAN}

Dari hasil yang telah dicapai bahwa untuk menentukan titik prioritas distribusi air berdasarkan indikator area dan kondisi lahan yang menjadi titik sensor dapat dilakukan dengan meningkatkan nilai $\alpha$ karena nilai ini dapat mempengaruhi kecendrungan terpilih berdasarkan kondisi tanah lebih tinggi seperti yang terlihat pada tabel 3 diatas sebaliknya jika pengaruh nilai $\alpha$ lebih rendah terhadap nilai $\tau_{i, j}^{\alpha}$ dan pengaruh nilai $\beta$ lebih besar maka kecendrungan air didistribusikan berdasarkan tingkat kekeringan tanah lebih rendah dan kecendrungan air didistribusikan berdasarkan Panjang pipa dan tingkat kemiringan tanah lebih besar Berikut adalah grafik hasil pengujian: 


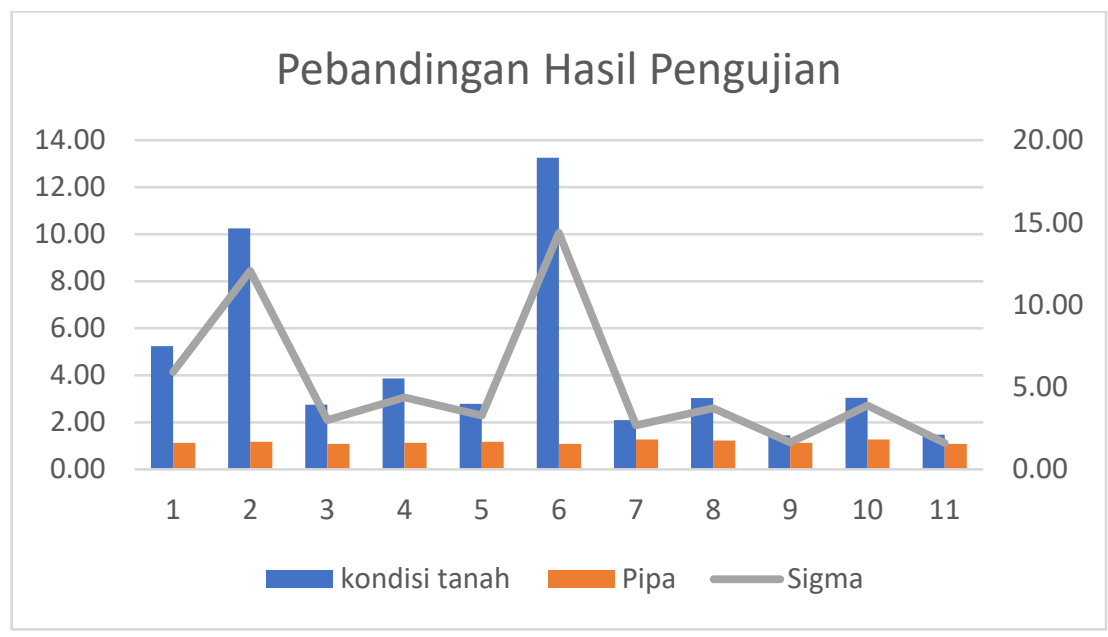

Gambar 2. Grafik Pebandingan Hasil Pengujian

Berdasarkan gambar 2 menunjukan kecendrungan untuk mendistribusikan air berdasarkan kondisi tanah ini dikarenakan nilai $\alpha$ sangat mendominasi dibandingkan dengan nilai $\beta$ seperti yang ditampilkan pada tabel 2 diatas. Kemudian hasil pengujian yang terkait dengan energi yang digunakan rata - rata untuk untuk kebutuhan 250 watt mesin pompa penyedot air adalah sekitar 4 buah panel surya dengan spesifikasi $150 \mathrm{wp}$ masing-masing panel surya yang di konversikan dengan inverter 1500 watt dan kapasitas baterai ukuran 24 volt cukup baik jika digunakan rata-rata 6 sampai 7 jam perhari untuk kebutuhan hanya 250 watt mesin pompa.

\section{KESIMPULAN DAN SARAN}

Dapat disimpulkan bahwa kebuutuhan air irigasi dapat menjadi solusi bagi lahan tada hujan dan sistem irigasi ini dapat memberikan solusi yang terbaik bagi masyarakat, sementara untuk distribusi air dengan dengan menggunakan algoritma ini tingkat akurasinya cukup baik dengan hanya mengatur 2 indikator saja yakni nilai $\alpha$ yang mempengaruhi tingkat keterpilihan berdasarkan tingkat kekeringan tanah dan nilai $\beta$ sebagai indicator Panjang pipa dan tingkat kemiringan tanah namun untuk menentukan ke dua nilai tersebut perlu dilakukan cara yang tepat dan kajian yang mendalam mengingat dalam paper ini penentuan kedua nilai tersebut masih ditentukan secara acak dan dalam paper ini belum melakukan pengukuran dan perhitungan secara spesifik tentang penggunaan energi yang dihasilkan dan digunakan pada pembangkit listrik tenaga suryanya hal ini juga dapat dilakukan penelitian khusus terkait dengan hal tersebut. Sebagai saran untuk pengembangan selanjutnya adalah perlu dilakukan cara yang lebih baik dalam menentukan nilai $\alpha$ dan nilai $\beta$ sehingga distribusi dapat lebih optimal dan berikutnya pada penggunaan panel surya perlu dilakukan kajian terkait dengan penggunaan energi yang paling tepat dan optimal sehingga penggunaan energi dapat lebih hemat.

\section{UCAPAN TERIMA KASIH}

Ucapan terima kasih kami sampaikan kepada semua pihak yang telah membantu dalam pelaksanaan penelitian dan penulisan paper ini baik yang secara langsung maupun yang tidak langsung. 


\section{DAFTAR PUSTAKA}

[1] S. L. Kering and U. Kurnia, "Prospek pengairan pertanian tanaman semusim lahan kering," vol. 1, no. 98, 2004.

[2] P. Analisis, S. Ekonomi, D. Kebijakan, P. Badan, L. Pertanian, and J. A. Yani, "Partisipasi Sebagai Strategi Pemberdayaan Petani Miskin Melalui Program Integrasi Jagung Dan Ternak 1 Roosgandha Elizabeth," pp. 1-15.

[3] I. Kholiq, "Pemanfatan Energi Alternatif Sebagai Eenergi Terbarukan Untuk Mendukung Substitusi BBM," Curr. Opin. Environ. Sustain., vol. 4, no. 1, p. i, 2012.

[4] haris abdul, "Sistem Kendali Pembatas Pemakaian Energi Listrik Berbasis Web," 2014.

[5] A. Haris and E. Hendrian, "Sistem Monitoring dan Klaster Ketersediaan Energi Menggunakan Metode K-Means pada Pembangkit Listrik Tenaga Surya,” vol. 4, no. 2, pp. 266-271, 2019.

[6] G. Pikra, A. Salim, B. Prawara, A. J. Purwanto, T. Admono, and Z. Eddy, "Development of small scale concentrated solar power plant using organic Rankine cycle for isolated region in Indonesia," Energy Procedia, vol. 32, pp. 122-128, 2013.

[7] A. Haris, "Sistem Pencatat Kwh Meter Terintegrasi Komputer Untuk Meningkatkan Layanan Pada Pelanggan," 2019. 